\title{
Нозокомиальная пневмония у больных хронической обструктивной болезнью легких
}

ФГУ "НИИ пульмонологии" ФМБА России: 105077, Москва, ул. 11-я Парковая, 32, к. 4

\section{S.N.Avdeev, G.E.Baymakanova, P.A.Zubairova, A.G.Chuchalin \\ Nosocomial pneumonia in patients with COPD}

\begin{abstract}
Summary
Nosocomial pneumonia (NP) is one of widespread in-hospital infectious diseases. Chronic obstructive pulmonary disease is one of risk factors of NP. The aim of this study was to investigate features of NP and a role of inflammatory biomarkers in patients with COPD and NP.

One hundred and eighty four patients with acute exacerbation of COPD were involved. Of them, $22(11.9 \%)$ patients developed pneumonia while staying in a hospital (18 males, 4 females, mean age, $66.0 \pm 11.02$ years). The CPIS scale was $9.4 \pm 2.1$ for all the NP patients, Charlson's co-morbidity index was $7.9 \pm 2.5$. In $90.9 \%$ of the patients, NP occurred in 5 days after admission. The following microorganisms were identified: Pseudomonas aeruginosa (5), Staphylococcus aureus (4), Streptococcus pneumoniae (4), Acinetobacter spp. (3). Mechanical lung ventilation was required in $13.6 \%$, non-invasive lung ventilation was required in $36.4 \%$ and supplemental oxygen was used in $90.9 \%$ of the patients. The mean length of hospitalization of COPD patients with NP was $42.6 \pm 20.3$ days; $27.3 \%$ of patients died. Serum levels of C-reactive protein (CRP) increased significantly in a day of diagnosis of NP compared to the baseline values: $105.5(83.3-145.8) \mathrm{mg} / \mathrm{L} v s 14.5(12.0-29.3) \mathrm{mg} / \mathrm{L}$ $(p<0.0001)$. Changes in CPR concentration allowed prediction the prognosis of NP patients $(p=0.002)$.

Therefore, NP typically has severe course with significant systemic inflammatory response and acute respiratory failure in patients with COPD. Apart from the APACHE II scale, inflammatory biomarkers could facilitate predicting prognosis and outcomes of NP. Key words: nosocomial pneumonia, COPD, inflammatory biomarkers.
\end{abstract}

\section{Резюме}

Нозокомиальная пневмония (НП) - одно из наиболее часто встречающихся в стационаре инфекционных заболеваний. Одним из факторов риска развития НП является хроническая обструктивная болезнь легких (ХОБЛ). Целью исследования стало изучение особенностей НП и роли биомаркеров воспаления у больных ХОБЛ. Были обследованы 184 пациента с обострением ХОБЛ. У $22(11,9 \%)$ больных пневмония развилась в условиях стационара. Среди них - 18 мужчин и 4 женщины; средний возраст составил $66,0 \pm 11,02$ года. Значение шкалы CPIS для всех больных ХОБЛ с НП составило 9,4 $\pm 2,1$ балла, индекс коморбидности Charlson - 7,9 $\pm 2,5$ балла. У $90,9 \%$ больных НП развилась после 5 дней пребывания в стационаре. У больных были выделены следуюшие микроорганизмы: Pseudomonas aeruginosa (5), Staphylococcus aureus (4), Streptococcus pneumoniae (4), Acinetobacter spp. (3). Проведение инвазивной вентиляции легких потребовалось $13,6 \%$, неинвазивной вентиляции легких - 36,4\%, оксигенотерапии - 90,9\% больных. Средняя продолжительность госпитализации больных ХОБЛ с НП составила 42,6 \pm 20,3 дней, умерли 27,3 \% пациентов. Концентрации сывороточного С-реактивного белка (СРБ) в день развития НП значительно превышали их исходные значения: $105,5(83,3-145,8)$ мг / л vs $14,5(12,0-29,3)$ мг / л $(p<0,0001)$. Динамика СРБ позволяла предсказать прогноз больных НП $(p=0,002)$.

Таким образом, НП у больных ХОБЛ характеризуется тяжелым течением, выраженной системной воспалительной реакцией и острой дыхательной недостаточностью. Наряду со шкалой АРАСНЕ II биомаркеры воспаления позволяют определить прогноз и исходы НП. Ключевые слова: нозокомиальная пневмония, ХОБЛ, биомаркеры воспаления.

Нозокомиальная пневмония (НП) является одним из наиболее часто встречающихся в стационаре инфекционных заболеваний [1]. Развитие НП приводит к увеличению числа осложнений, удлинению сроков госпитализации, повышению затрат здравоохранения и увеличению летальности больных [2, 3]. Самая высокая распространенность НП отмечается в отделениях реанимации и интенсивной терапии (ОРИТ), особенно среди пациентов, требующих проведения искусственной вентиляции легких (ИВЛ) [4-9]. В настоящее время, несмотря на успехи антибиотикотерапии, НП остается основной причиной летальности больных ОРИТ [3, 10-12]. В то же время частота развития НП достаточно высока и у больных, госпитализированных в нереанимационные отделения [13-17], однако число исследований, посвященных данной проблеме, пока крайне мало [18-21].

Одним из факторов риска развития НП является хроническая обструктивная болезнь легких (ХОБЛ).
Летальность среди пациентов ХОБЛ при госпитальных пневмониях достигает 41,7 \% [22]. О наличии инфекции нижних дыхательных путей свидетельствуют такие классические признаки, как лихорадка, тахипноэ, лейкоцитоз периферической крови и тахикардия [23, 24]. Однако, несмотря на относительно высокую информативность этих симптомов, их трактовка не всегда может быть однозначной, особенно при сложном коморбидном фоне, т. к. все данные признаки у больных ХОБЛ могут быть обусловлены неинфекционными причинами $[25,26]$. В такой сложной диагностической ситуации большое значение могут играть биомаркеры системного воспаления, однако, опять же, исследований, посвященных роли биомаркеров в диагностике НП у больных ХОБЛ, практически нет.

Целью нашего исследования стало изучение особенностей НП и роли биомаркеров воспаления у больных ХОБЛ. 


\section{Материалы и методы}

Всего были обследованы 184 пациента с обострением ХОБЛ. У 22 (11,9 \%) из них пневмония развилась в условиях стационара. Среди них были 18 мужчин и 4 женщины, средний возраст больных составил $66,0 \pm 11,02$ года (табл. 1). Диагноз ХОБЛ был подтвержден данными анамнеза, клинической картины, рентгенологическими и функциональными методами диагностики [27]. НП определялась как появление "новых" инфильтративных затемнений на рентгенограмме грудной клетки и наличие симптомов инфекционного заболевания нижних дыхательных путей (лихорадка, лейкоцитоз, кашель, продукция гнойной мокроты, усиление диспноэ, "плевритические" боли в грудной клетке [2, 23, 24]. Кроме того, для подтверждения диагноза НП у госпитализированных больных была использована шкала CPIS ( $\geq 6$ баллов свидетельствовали о развитии НП) [28, 29].

У всех больных оценивались демографические показатели, стаж курения, индекс массы тела (ИМТ), симптомы и физикальные признаки, общая тяжесть состояния, рентгенография грудной клетки, общий и биохимический анализ крови, газы артериальной крови, сопутствующие заболевания, предшествующая терапия, проведение курсов терапии системными кортикостероидами, число госпитализаций в течение последнего года. При необходимости больным проводилась компьютерная томография легких и фибробронхоскопия (ФБС).

Общая оценка тяжести заболевания проводилась с помощью шкалы АРАCHI II [30]. Индекс коморбидности Charlson определялся с учетом возраста больных и наличия у них определенных сопутствующих заболеваний [31]. Синдром системного воспалительного ответа (ССВО) оценивался по критериям Surviving Sepsis Campaign (2008) [32].

Оценка клинических симптомов, таких как кашель и объем мокроты, проводилась по 4-балльной шкале: 0 - нет симптома, 1 - слабая выраженность симптома, 2 - умеренная выраженность симптома, 3 - сильная выраженность симптома. Оценка диспноэ проводилась по русскоязычной версии шкалы Borg [33].

Материалом для бактериологического анализа служила мокрота, полученная после глубокой экспекторации или жидкость бронхоальвеолярного лаважа (БАЛ), полученного во время ФБС. Все образцы, удовлетворявшие критериям Murrey-Wasington ( $<10$ эпителиальных клеток и $>25$ лейкоцитов в поле зрения; ×100), исследовали на бактериальные культуры [34]. Чувствительность изолятов к антибактериальным препаратам определяли диско-дифузионным способом [35].

Уровень С-реактивного белка (СРБ) в сыворотке крови измеряли иммунометрическим методом с помошью системы NycoCard II Test Kit (Axis-Shield of Oslo, Норвегия). Концентрацию в сыворотке крови интерлейкина-6 (IL-6), фактора некроза опухоли- $\alpha$ (TNF- $\alpha$ ) определяли на оборудовании Tecan Sunrise (Tecan Trading $A G$, Щвейцария) с использованием иммуноферментных наборов для количественного определения биомаркеров (Biosource, США, Бельгия); концевого мозгового натриуретического пептида (Nt-pro-BNP) - с помощью тестовой системы Biomedica. Рутинное измерение СРБ осуществляли при поступлении в стационар (СРБ $)$, при подозрении на развитие НП (СРБ $)$ и на 5-10-й день, в зависимости от динамики клинической картины НП $\left(\mathrm{CPБ}_{2}\right)$. Концентрацию остальных биомаркеров (IL-6, TNF- $\alpha$ и Nt-pro-BNP) определяли только на момент развития НП.

Газовый анализ артериальной крови проводили экспресс-методом на автоматическом анализаторе ABL-500 (Radiometer Copenhagen, Дания). Забор артериальной крови осуществлялся из лучевой артерии с помощью гепаринизированного шприца.

Статистическая обработка результатов была проведена при помощи пакета прикладных программ SPSS 13 for Windows. Все численные данные представлены как mean $\pm S D$ или Mediana $(M)$ с 25-75\%-ным интерквартильным размахом (IQR) и в абсолютных числах с указанием процентов. Достоверность различий одноименных количественных показателей между группами определялась при помощи критерия Манна-Уитни (U-test). Для определения диагностической ценности маркеров был использован ROC-анализ. Корреляционный анализ представлен с помощью Spearman rank correlation. Различия считались статистически достоверными при $p<0,05$.

\section{Результаты и обсуждение}

Характеристика 22 пациентов с ХОБЛ и НП представлена в табл. 1. Среднетяжелое течение ХОБЛ

таблица 1

Характеристика пациентов с ХОБЛ и НП

\begin{tabular}{|lc|}
\hline Параметры & Значения \\
\hline Мужчины, $n$ (\%) & $18(81,8)$ \\
\hline Женщины, $n$ (\%) & $4(18,1)$ \\
\hline Средний возраст, лет & $66,0 \pm 11,0$ \\
\hline ИМт, кг / м² & $25,1 \pm 7,6$ \\
\hline Стаж курения, пачек / лет & $46,0 \pm 17,2$ \\
\hline Стадии ХОБЛ, $n$ (\%) & \\
$\quad$ II & $2(9,1)$ \\
\hline III & $12(54,5)$ \\
\hline IV & $8(36,4)$ \\
\hline Длительность ХОБЛ, лет & $11,7 \pm 4,5$ \\
\hline Частота обострений в год & $3,3 \pm 0,9$ \\
\hline ФЖЕЛ, \% & $65,2 \pm 15,8$ \\
\hline ОФВ, \% & $34,3 \pm 11,1$ \\
\hline СДЛА, мм рт. ст & $43,8 \pm 9,7$ \\
\hline Оксигенотерапия на дому, $n$ (\%) & $5(22,7)$ \\
\hline Прием иГКС, $n$ (\%) & $16(72,7)$ \\
\hline Прием сГКС, $n$ (\%) & $4(18,2)$ \\
\hline Прием антибиотиков в последние 3 мес., $n$ (\%) & $17(77,3)$ \\
\hline Прием ингибиторов протонной помпы, $n$ (\%) & $18(81,8)$ \\
\hline
\end{tabular}

Примечание: ФЖЕЛ - форсированная жизненная емкость легких; ОФВ 1 - объем форсированного выдоха за 1-ю с; СДЛА - систолическое давление в легочной артерии. 
Таблица 2

Сопутствующая патология у больных ХОБЛ с НП

\begin{tabular}{|l|c|}
\multicolumn{1}{c|}{ Заболевание } & $n(\%)$ \\
Индекс коморбидности Charlson, баллы & $7,9 \pm 2,5$ \\
\hline ИБС & $16(72,7)$ \\
\hline Артериальная гипертензия & $19(86,3)$ \\
\hline Сердечная недостаточность (ФВ ЛЖ <50 \%) & $1(4,5)$ \\
\hline ЯБ и ГЭРБ & $7(31,8)$ \\
\hline Сахарный диабет & $4(18,2)$ \\
\hline ХВН & $6(27,3)$ \\
\hline ЦВБ & $15(68,2)$ \\
\hline Болезни печени & $7(31,8)$ \\
\hline Новообразования & $3(13,6)$ \\
\hline
\end{tabular}

Примечание: ФВ ЛЖ - фракция выброса левого желудочка; ЯБ - язвенная болезнь (желудка или 12-перстной кишки); гЭРБ - гастроэзофагеальная рефлюксная болезнь; ЦВБ - цереброваскулярная болезнь; ХВН - хроническая венозная недостаточность.

отмечено у 2 (9,1\%), тяжелое течение - у $12(54,5 \%)$, крайне тяжелое течение ХОБЛ - у $8(36,4 \%)$ больных. Длительную оксигенотерапию на дому получали $5(22,7 \%)$ человек. В амбулаторных условиях ингаляционные глюкокортикостероиды (иГКС) принимали 16 (72,2\%), системные (сГКС) - $4(18,2 \%)$ больных, предшествующая терапия антибиотиками проводилась 95,5\%, терапия ингибиторами протонной помпы - 81,8\% больных.

Большинство пациентов имели по 2-4 сопутствующих фоновых заболевания, среди которых преобладали ишемическая болезнь сердца - ИБС $(72,7 \%)$, артериальная гипертензия (86,3\%), цереброваскулярная болезнь $(68,2 \%)$. Индекс коморбидности Charlson составил 7,9 $\pm 2,5$ балла (табл. 2).

Большинство пациентов были госпитализированы в пульмонологическое отделение (15 / 68,1 \%), остальные переведены из аллергологического (3 / $13,6 \%)$, хирургического (3 / 13,6 \%) и неврологического $(1 / 4,5 \%)$ отделений. У почти половины боль-

Таблица 3

Клиническая картина НП у больных ХОБЛ

\begin{tabular}{|l|c|}
\hline \multicolumn{1}{|c|}{ Параметры } & 3начения \\
\hline Средняя t, ${ }^{\circ}$ C & $37,9 \pm 0,7$ \\
\hline Кашель, балл & $1,3 \pm 0,6$ \\
\hline Мокрота, балл & $1,6 \pm 0,7$ \\
\hline Кровохарканье, $n$ (\%) & $2(9,1)$ \\
\hline Боли в грудной клетке, $n$ (\%) & $11(50,0)$ \\
\hline Цианоз, $n$ (\%) & $20(90,9)$ \\
\hline чДД, мин ${ }^{-1}$ & $30,9 \pm 9,7$ \\
\hline Одышка по шкале Borg, баллы & $7,9 \pm 1,9$ \\
\hline Sр02, \% & $77,6 \pm 10,3$ \\
\hline чСС, мин ${ }^{-1}$ & $115,0 \pm 19,2$ \\
\hline АДс, мм рт. ст. & $130,0 \pm 17,5$ \\
\hline АДд, мм рт. ст. & $79,1 \pm 9,2$ \\
\hline АРАСНЕ II, баллы & $20,5 \pm 6,0$ \\
\hline СРІS, баллы & $9,4 \pm 2,1$ \\
\hline ССВО, $n$ (\%) & $20(90,9)$ \\
\hline
\end{tabular}

Примечание: ЧдД - частота дыхательных движений, $\mathrm{SpO}_{2}$ - насыщение артериальной крови кислородом, ЧСС - частота сердечных сокращений, АДс - систолическое артериальное давление, АДд - диастолическое артериальное давление, ССВО - синдром системной воспалительного ответа.
Таблица 4

Лабораторные показатели у больных ХОБЛ и НП

\begin{tabular}{|c|c|}
\hline Параметры & Значения \\
\hline Гемоглобин, г / л & $125,2 \pm 27,7$ \\
\hline Лейкоциты крови, $\times 10^{9}$ / л клеток & $12,1 \pm 4,4$ \\
\hline Глюкоза крови, моль / л & $6,2 \pm 3,9$ \\
\hline Мочевина, мкмоль / л & $6,5 \pm 1,8$ \\
\hline $\mathrm{pH}$ & $7,38 \pm 0,04$ \\
\hline $\mathrm{PaCO}_{2}$, мм рт. ст. & $51,4 \pm 13,8$ \\
\hline $\mathrm{PaO}_{2}$, мм рт. ст. & $47,8 \pm 9,9$ \\
\hline $\mathrm{CPБ}_{0}, \mathrm{Mr} / \mathrm{л}$ & $14,5(12,0-29,3)$ \\
\hline $\mathrm{CPБ}_{1}, \mathrm{Mr} / \pi$ & $105,5(83,3-145,8)$ \\
\hline $\mathrm{CPБ}_{2}, \mathrm{Mr} / \boldsymbol{л}$ & $20,5(10,0-107,8)$ \\
\hline Nt-proBNP, фмоль / л & $1128,7(732,7-1356,7)$ \\
\hline IL-6, пг / мл & $29,3(9,4-245,1)$ \\
\hline TNF- $\alpha$, пг / мл & $6,6(4,5-8,1)$ \\
\hline
\end{tabular}

Примечание: СРБ - уровень СРБ в день госпитализации; СРБ 1 - уровень СРБ при развитии НП, СРБ 2 - уровень СРБ в динамике.

ных (10 / 45,5 \%) во время госпитализации было передвижение по $\geq 2$ отделениям, включая ОРИТ.

Клиническая характеристика НП у больных ХОБЛ представлена в табл. 3. У половины больных наблюдались боли в грудной клетке (50\%). НП сопровождалась синдромом системного воспалительного ответа (90,9 \%), признаками дыхательной недостаточности (ДН), цианозом, одышкой, тахипноэ и тахикардией (табл. 3), лейкоцитозом, гипоксемией и гиперкапнией (табл. 4).

Раннее развитие НП - в течение 5 дней госпитализации - наблюдалось у 2 (9,1\%) больных, у остальных пациентов $(90,9 \%)$ - после 5 дней пребывания в стационаре; в среднем, НП развивалась на $18,1 \pm 9,3$ дня госпитализации. У 2 пациентов было 2 эпизода НП, у 1 пациента НП развилась после разрешившейся внебольничной пневмонии (ВП). Сре-

Таблица 5 Характеристика больных по шкале клинической ощенки инфекции легких CPIS при подозрении на НП

\begin{tabular}{|c|c|c|}
\hline Параметр & Значение & $n(\%)$ \\
\hline \multirow[t]{3}{*}{$t,{ }^{\circ} \mathrm{C}$} & $36,5-38,4$ & $8(36,4)$ \\
\hline & $38,5-39,0$ & $6(27,2)$ \\
\hline & $<36,0$ или $>39,0$ & $8(36,4)$ \\
\hline \multirow[t]{2}{*}{ Лейкоцитоз, $\times 10^{3} /$ мл } & $4-11$ & $7(31,8)$ \\
\hline & $<4$ или > 11 & $15(68,2)$ \\
\hline Характер секрета & нет & - \\
\hline \multirow[t]{2}{*}{ (мокроты или БАЛ) } & негнойный & $2(9,1)$ \\
\hline & гнойный & $20(90,9)$ \\
\hline \multirow[t]{2}{*}{$\mathrm{PaO}_{2} / \mathrm{FiO}_{2}$, мм рт. ст. } & $>240$ & $5(22,7)$ \\
\hline & $<240$ & $17(77,3)$ \\
\hline Рентгенологические & нет & - \\
\hline \multirow[t]{2}{*}{ инфильтраты } & диффузные (пятнистые) & $15(68,2)$ \\
\hline & локализованные & $7(31,8)$ \\
\hline Прогрессирование & нет & $13(59,1)$ \\
\hline процесса в легких & да & $9(40,9)$ \\
\hline \multirow[t]{2}{*}{$\begin{array}{l}\text { Культуральное исследование } \\
\text { секрета (мокроты или БАЛ) }\end{array}$} & $\begin{array}{l}\text { малое количество патоге- } \\
\text { нов или отсутствие роста }\end{array}$ & $7(31,8)$ \\
\hline & $\begin{array}{l}\text { умеренное или значитель- } \\
\text { ное количество патогенов }\end{array}$ & $15(68,2)$ \\
\hline
\end{tabular}


ди возможных факторов риска развития НП можно отметить низкую физическую активность больных, в т. ч. полный постельный режим, проведение ФБС $(9,1 \%)$, трахеостомии $(4,5 \%)$, катетеризации центральных вен $(36,4 \%)$, хирургических операций $(9,1 \%)$ и развитие комы $(4,5 \%)$.

Клинико-рентгенологические, лабораторные данные по параметрам шкалы CPIS при оценке наличия НП представлены в табл. 5.

Значение шкалы CPIS для всех больных равнялось 9,4 \pm 2,1 балла. У 4 пациентов подсчет баллов шкалы CPIS соответствовал 6, у остальных - > 6 баллов. Рентгенологически локализованные инфильтраты в легких отмечались в 31,8 \% случаев, диффузные, пятнистые инфильтраты - в 68,2 \% случаев. У 8 (36,4 \%) пациентов развились осложнения: плеврит - у $2(9,1 \%)$, абсцесс - у $5(22,7 \%)$, ателектаз у $1(4,5 \%)$.

Микробиологические исследования у наблюдаемых нами больных показали наличие монокультур микроорганизмов в 78,5 \% и ассоциации микроорганизмов - в 21,5\% случаев. Всего идентифицировано в значимых концентрациях 16 штаммов возбудителей. Среди выделенных штаммов микроорганизмов лидирующее место занимала $P$. aeruginosa (5), затем следовали $S$. aureus (4), S. pneumoniae (4), Acinetobacter spp. (3), реже встречалась Klebsiella pneumoniae (1). Ассоциации микроорганизмов были представлены P. aeruginosa и Acinetobacter spp. (2), S. pneumoniae и $S$. aureus (1). У умерших пациентов спектр возбудителей был представлен $P$. aeruginosa (1), S. aureus (2) и $S$. pneumoniae (1).

Концентрации сывороточного СРБ значимо повышались при развитии НП, по сравнению с исходными значениями, в 1-е дни госпитализации: 105,5 $(83,3-145,8)$ мг / л и 14,5 $(12,0-29,3)$ мг / л соответственно $(p<0,0001)$. Уровни СРБ 1 и СРБ 2 у больных с НП коррелировали со шкалой CPIS $(r=0,518$, $p=0,014$ и $r=0,440, p=0,040$ соответственно), со шкалой АРАСНЕ II коррелировали концентрации сывороточных биомаркеров IL-6 и СРБ $(r=0,679$, $p=0,003$ и $r=0,656, p=0,003$ соответственно). Положительная корреляционная связь отмечалась между баллами шкал АРАСНЕ II и CPIS ( $r=0,504$, $p=0,017)$ (табл. 6).

Проведение респираторной поддержки потребовалось половине (50 \%) больных ХОБЛ с НП: ИВЛ -

Таблица 6 Взаимосвязь маркеров воспаления со значениями шкал CPIS и APACHE II

\begin{tabular}{|c|c|c|c|c|}
\hline \multirow{2}{*}{$\begin{array}{c}\text { Шкала } \\
\text { показатель }\end{array}$} & \multicolumn{2}{|c|}{ APACHE II } & \multicolumn{2}{|c|}{ CPIS } \\
\hline & $r$ & $p$ & $r$ & $p$ \\
\hline $\mathrm{CPБ}_{1}, \mathrm{Mr} / \boldsymbol{л}$ & 0,341 & 0,121 & 0,518 & 0,014 \\
\hline $\mathrm{CPБ}_{2}, \mathrm{Mг} /$ л & 0,656 & 0,001 & 0,440 & 0,040 \\
\hline Nt-pro-BNP, фмоль / л & 0,240 & 0,283 & $-0,139$ & 0,593 \\
\hline IL-6, пг / мл & 0,679 & 0,003 & 0,157 & 0,549 \\
\hline TNF- $\alpha$, пг / мл & $-0,026$ & 0,932 & $-0,140$ & 0,534 \\
\hline $\begin{array}{l}\text { Лейкоциты крови, } \\
\text { × 109 / л клеток }\end{array}$ & $-0,068$ & 0,767 & 0,139 & 0,539 \\
\hline
\end{tabular}

Таблица 7

Уровень биомаркеров воспаления у выживиих и умерших больных НП

\begin{tabular}{|l|c|c|c|}
\hline Показатель & Выжившие $(n=16)$ & Умершие $(n=6)$ & $p$ \\
\hline СРБ $_{1}$, мг / л & $105,0(78,3-143,3)$ & $120,5(78,5-183,5)$ & 0,555 \\
\hline СРБ $_{2}$, мг / л & $13,5(7,8-24,5)$ & $122,5(79,5-187,5)$ & 0,002 \\
\hline Nt-proBNP, & & & \\
фмоль / л & $1128,7(716,1-1315,4)$ & $1225,1(946-1359,3)$ & 0,598 \\
\hline IL-6, пг / мл & $23,8(8,6-47,4)$ & $289,0(29,3-500,0)$ & 0,033 \\
\hline TNF- $\alpha$, пг / мл & $6,6(6,6-7,3)$ & $5,9(2,5-8,5)$ & 0,712 \\
\hline
\end{tabular}

$3(13,6 \%)$, НВЛ - $8(36,4 \%)$; оксигенотерапию в условиях стационара проводили 20 (90,9 \%) пациентам. Перевод в ОРИТ по поводу НП понадобился 16 (72,7 \%) больным. Средняя продолжительность госпитализации пациентов с ХОБЛ и НП составила $42,6 \pm 20,3$ дней. Во время госпитализации умерли $6(27,3 \%)$ пациентов. Непосредственной причиной смерти 5 больных была НП с развитием острой дыхательной недостаточности, 1 - полиорганная недостаточность. В течение последующих 6 мес. наблюдения умерли 11 (50,0 \%) больных ХОБЛ.

Как видно из табл. 5, сравнение уровней биомаркеров воспаления показал достоверное повышение продукции IL-6 у умерших пациентов по сравнению с выжившими $(p=0,033)$. Кроме того, летальный исход при НП у больных ХОБЛ был связан с отрицательной динамикой СРБ: уровень СРБ 2 был значительно выше у умерших по сравнению с выжившими $(p=0,002)$.

При ROC-анализе оценки прогностической значимости биомаркеров и шкалы АРАСНЕ II было показано, что наибольшую ценность для предсказания неблагоприятного исхода больных ХОБЛ с НП имели значения шкалы АРАCHE II (площадь под ROCкривой $-0,922 ; 95 \%$-ный доверительный интервал

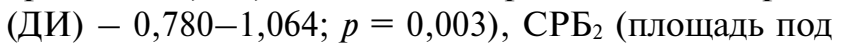
ROC-кривой - 0,983; 95\%-ный ДИ - 0,837-1,038; $p=0,002)$, IL-6 (площадь под ROC-кривой - 0,833; $95 \%$-ный ДИ - 0,641-1,026; $p=0,035)$.

Особенностью нашего исследования является изучение случаев НП, развившейся у больных ХОБЛ в условиях нереанимационных отделений стационара. Распространенность НП среди госпитализированных больных ХОБЛ составила 11,9 \% случаев. В одном из немногих доступных на сегодня исследований, посвященных НП, которая развилась вне ОРИТ, распространенность НП составила $3 \pm 1,4$ случая на 1000 госпитализаций [20]. Большинство пациентов, включенных в данное исследование, находились в терапевтических палатах стационара $(64,2 \%)$ и имели тяжелые сопутствующие заболевания $(66,6 \%)$ [20]. Преобладающее число пациентов с НП в терапевтических отделениях объясняется более частым наличием у них сопутствующей патологии и более длительными сроками госпитализации по сравнению с хирургическими больными. Длительная госпитализация является другим известным фактором риска развития НП [9], и в исследовании N.Sopena et al. у большинства пациентов на момент 
развития НП сроки госпитализации превышали 5 дней $(84,7 \%)[20]$.

Среди пациентов, включенных в наше исследование, преобладали люди пожилого и старческого возраста, преимушественно мужчины, имевшие сложный коморбидный фон. У 90,9 \% изученных нами больных НП развилась после 5 дней пребывания в стационаре. В большинстве случаев развитию НП способствовали низкая физическая активность пациентов, проведение ФБС, трахеостомии, катетеризации центральных вен, хирургических операций и развитие комы. Таким образом, у обследованного нами контингента наблюдались факторы риска развития НП, подобные тем, которые были отмечены в других исследованиях $[3,9,10,12,14,18-20]$. Так, в уже упомянутом исследовании N.Sopena et al. большинство пациентов с НП были старше 60 лет, и у $3 / 4$ пациентов была выявлена сопутствующая патология, главным образом, опухоли, ХОБЛ, сахарный диабет, сердечная недостаточность, которые были фатальными или, в конечном счете, фатальными у $2 / 3$ больных [20].

В некоторых исследованиях также были выявлены дополнительные факторы риска развития НП, такие как проводимая лекарственная терапия (антибиотики, блокаторы Н2-гистаминновых рецепторов, ГКС) [5, 9, 13-17, 20]. Среди наших пациентов абсолютное большинство до госпитализации получали ингаляционные (72,2 \%) и системные ГКС (18,2\%), а также антибиотики $(95,5 \%)$ и ингибиторы протонной помпы $(81,8 \%)$, что, возможно, также следует отнести к факторам риска НП у больных ХОБЛ.

У большинства больных НП, включенных в наше исследование, было отмечено наличие ХОБЛ тяжелого и крайне тяжелого течения. Большинство из них поступили в стационар именно с обострением ХОБЛ. Сама по себе ХОБЛ является фактором риска госпитальных инфекций нижних дыхательных путей $[36,37]$, в т. ч. НП [22]. У больных ХОБЛ имеются факторы, предрасполагающие к развитию НП, такие как трахеобронхиальная колонизация, воспаление дыхательных путей, нарушения в звеньях системной и местной защиты [36, 37].

В доступной на сегодня литературе данные по НП у больных ХОБЛ очень немногочисленны. Исследование S.Nseir et al. явилось одним из первых, в котором авторы изучали влияние вентилятор-ассоциированной пневмонии (ВАП) на исходы пациентов с ХОБЛ [36]. Среди выборки больных ХОБЛ, включавшей 1080 пациентов, ВАП развилась у 77 (7\%). Летальность в ОРИТ (64\% vs $28 \%$ ), длительность респираторной поддержки $(24 \pm 15$ vs $13 \pm$ 11 дней) и длительность нахождения больных в ОРИТ (26 \pm 17 vs $15 \pm 13$ дней) были значительно выше у больных ВАП, по сравнению с больными без ВАП $(p<0,001)$. Авторы исследования сделали вывод, что высокая атрибутивная летальность от ВАП у больных ХОБЛ может быть связана с пожилым возрастом, высокой частотой ВАП, ассоциированной с мультирезистентными патогенами, и высокой частотой позднего развития ВАП. J.Rello et al. [38] также продемонстрировали, что наличие ХОБЛ было связано с более высокими показателями летальности у пациентов с ВАП, однако после коррекции статистической модели ХОБЛ не была причислена к независимым предикторам летальности у больных ВАП.

Клиническая картина НП у наших пациентов с ХОБЛ характеризовалась наличием синдрома системного воспалительного ответа - ССВО (90,9 \%) и признаками ДН (цианозом, одышкой, тахипноэ, гипоксемией и гиперкапнией). Значение шкалы CPIS для всех больных равнялось 9,4 \pm 2,1 балла. Проведение респираторной поддержки потребовалось половине (50 \%) больных, госпитализация в ОРИТ была необходима $72,7 \%$, а внутригоспитальная летальность составила 27,3 \% случаев. Полученные нами результаты позволяют сделать вывод, что НП у больных ХОБЛ характеризуется тяжелым течением, усугублением уже имеющейся ДН, высокой потребностью в респираторной поддержке и высокой летальностью.

Результаты нашего исследования подтверждаются и другими авторами. Так, в вышеупомянутом исследовании N.Sopena et al. осложненное течение НП отмечалось у 52,1 \% пациентов: ДН - у 57 (34,5\%), плевральный выпот - у 34 (20,6 \%), септический шок - у 16 (9,6 \%), почечная недостаточность - у 8 $(4,8 \%)$ и эмпиема плевры - у 4 (2,4 \%) больных. Общая летальность больных НП в данной работе составила $26 \%$ [20]. В другом исследовании летальность среди пациентов с ХОБЛ и НП составила 41,7 \% [22].

Общая летальность и атрибутивная летальность от НП была выше у пациентов с неадекватной антибактериальной терапией, по сравнению с адекватным режимом лечения [20]. Общая летальность составила $75 \%$ (6 из 8 случаев) vs 22,4 \% (34 из 152 случаев) соответственно ( $p=0,003$, относительный риск (OР) - 10,41; 95\%-ный ДИ - 2,01-53,95), а атрибутивная летальность при НП - 50 \% (4 из 8 случаев) vs 15,1\% (23 из 152 случаев) соответственно $(p=0,02$; ОР - 4,92; 95\%-ный ДИ - 1,31-18,49) [20].

Как уже упоминалось, постановка этиологического диагноза НП часто затруднена в связи с ограниченностью применения инвазивных диагностических процедур. Возбудитель обычно определяется на основе результатов бактериологических посевов крови и мокроты или трахеального секрета. В связи с этим информация о возбудителях, ответственных за ВАП, сегодня хорошо изучена, а данные о возбудителях других госпитальных инфекций, исключая ВАП, пока достаточно противоречивы [9, 14-17]. Так, в исследовании J.Gomez et al. [18] у "некритических" пациентов этиологический диагноз НП был определен всего у 1/3 больных, основная причина этого - неспособность больных в большинстве случаев перенести инвазивные процедуры, в т. ч. ФБС. Кроме того, чувствительность бактериологических исследований не всегда бывает высокой [39, 40$]$.

Микробиологические исследования в нашем исследовании показали участие в развитии НП таких возбудителей, как $P$. aeruginosa, $S$. aureus, $S$. pneumonia и Acinetobacter spp. В связи с тяжестью состояния 
пациентов нам тоже не удалось провести ФБС всем больным. Следует заметить, что пациенты, представленные в нашем исследовании, в большинстве своем были с тяжелым и крайне тяжелым течением ХОБЛ. В связи с этим встречаемость таких возбудителей как P. aeruginosa, Acinetobacter spp. закономерна. Известный возбудитель ВП - S. pneumoniae - был высеян у 4 больных, что подтверждает роль этого микроорганизма в развитии НП, что также было показано и в исследовании N.Sopena et al. [20].

В многоцентровом испанском исследовании (165 больных) этиологическая структура НП представлена такими возбудителями, как S. pneumoniae, Legionella pneumophila, Aspergillus spp., P. aeruginosa и Enterobacteriaceae [20]. Авторы предлагают рассматривать такие возбудители, как S. pneumoniae и L. pneumophila, в качестве дополнительных патогенов к уже известным этиологическим факторам госпитальной инфекции [20]. Частота встречаемости грамотрицательных возбудителей, широко распространенных у пациентов ОРИТ, в данном исследовании оказалась ниже у пациентов с нетяжелым иммуносупрессивным состоянием. Большинство пациентов, включенных в исследование N.Sopena et al. [20], ранее не переносили ротоглоточных манипуляций, которые влияли бы на селекцию микробов, вызывающих пневмонию у "вентилируемых" больных [41-43]. Авторы предполагают, что нормальная микробная флора у этих пациентов сохраняется дольше, и такие микроорганизмы, как $S$. pneumoniae, могут играть важную роль и в развитии НП.

В исследовании B.Herer et al. с помощью брашбиопсии изучался этиологический спектр НП, также развившейся в общемедицинских палатах. Возбудитель был идентифицирован в 58,3\% случаев. Основными патогенами были Рseudomonas spp. (23,9\%), Enterobacteriaceae (23,3\%), Streptococcus spp. (21,6\%) и Staphilococcus spp. (13,1 \%). Ассоциации микроорганизмов встречались чаще у больных с трахеостомией $(p<0,01)$. Авторы показали, что распространенность возбудителей у "вентилируемых" и "невентилируемых" больных была сопоставимой [21].

Имеющиеся на сегодняшний день данные о СРБ при пневмонии позволяют говорить о хорошей диагностической и прогностической ценности данного биомаркера [44-47]. Снижение сывороточного уровня СРБ при пневмонии в течение 48 ч антибактериальной терапии было ассоциировано с частотой летальности 15,4 \%, тогда как повышенные концентрация СРБ ассоциировалась с летальностью в 60,9\% (OР - 0,25; 95\%-ный ДИ - 0,07-0,91; $p<0,05)$. Высокие концентрации СРБ и тяжесть болезни отражали паттерн мультиорганной недостаточности. S.M.A.Lobo et al. на основании полученных результатов предлагают включить СРБ в общие критерии тяжести больных, например такие, как АРАСНЕ II [48]. Полезность мониторинга СРБ для прогноза пневмонии продемонстрирована и в работе L.Coelho et al. [49]. В то же время, по данным других авторов, уровни СРБ не коррелировали с тяжестью болезни по шкале APACHE II [50]. Согласно данным S.A.Flanders et al., уровень СРБ не соотносился с тяжестью болезни и динамикой симптомов ВП [46].

Мониторинг СРБ у критически больных пациентов помогает в ранней диагностике внутрибольничной инфекции. Так в исследовании A.Matson et al. показано, что увеличение концентрации СРБ на $\geq 25 \%$ от предыдущего уровня свидетельствовало о наличии инфекционных осложнений [51]. В проспективном исследовании P.Povoa et al. изучалась роль СРБ, температуры тела, лейкоцитов крови для раннего выявления инфекции в ОРИТ [52]. Максимальные ежедневные колебания уровня СРБ > 41 мг / л от 1-го дня наблюдения были предиктором инфекции (чувствительность - 92,1\%, специфичность - 71,4\%). При логистическом регрессионном анализе 4 параметра (максимальный СРБ, изменение СРБ, температура тела и лейкоциты крови) были признаны хорошими предикторами инфекции $(p<0,05)$ [53]. Другое исследование тех же авторов включало в себя 47 больных с ВАП. Пациенты с быстрым и медленным ответом СРБ имели благоприятный исход, в то время как в других случаях тяжесть ВАП была выше, и смертность достигала $78 \%$ [52].

Несколько исследований продемонстрировали участие сывороточного цитокина IL-6 в патогенезе повреждения органов и летальных исходов у больных с тяжелыми инфекциями легких и сепсисом [54-57]. В 2 исследованиях было показано, что сывороточные уровни IL-6 у больных с тяжелой пневмонией и CCBO были значительно выше, чем у пациентов с пневмонией без ССВО $[57,58]$. У больных с пневмонией сывороточные уровни IL-6 коррелировали со степенью тяжести болезни и выраженностью полиорганной недостаточности [56-59]. Неинформативность TNF- $\alpha$ в нашем исследовании, возможно, объясняется преобладанием местных механизмов активации данного маркера. Так, TNF- $\alpha$ характеризуется коротким периодом полураспада, в связи с чем возможно пропустить пиковые концентрации этого цитокина при выполнении 1-кратного анализа [59].

В нашем исследовании уровни сывороточного СРБ значимо повышались при развитии НП по сравнению с исходными значениями данного биомаркера в 1-е дни госпитализации. Концентрации СРБ 1 и СРБ 2 при подозрении на НП коррелировали со шкалами CPIS и APACHE II. Уровень СРБ 1 коррелировал с IL-6. Кроме того, уровни СРБ 2 и IL-6 достоверно были повышены у умерших пациентов, по сравнению с выжившими. Прогностическое значение для больных НП и ХОБЛ в данном исследовании имели показатели шкалы APACHE II, CPБ 2 , IL-6.

Таким образом, НП у больных ХОБЛ характеризуется тяжелым течением, выраженной системной воспалительной реакцией и острой ДН. Наряду со шкалой АРАСНЕ II, биомаркеры воспаления (СРБ и IL-6) позволяют определить прогноз и исходы НП.

\section{Литература}

1. Strausbaugh L.J. Nosocomial respiratory infections. In: Mandel G.L., Benet J.E., Dolin R., eds. Principles and 
practice of infectious diseases. New York: Churchill Livingstone; 2000. 3020-3028.

2. Чучалин А.Г., Гельфанд Б.Р. (ред.). Нозокомиальная пневмония у взрослых: Российские нац. рекомендации. М.: Боргес; 2009.

3. Craven D.E., Steger K.A. Epidemiology of nosocomial pneumonia: new perspectives on an old disease. Chest 1995; 108 (2, Suppl.): S1-S16.

4. Vincent J.L., Bihari D.J., Suter P.M. et al. The prevalence of nosocomial infection in intensive care units in Europe: results of the European Prevalence of Infection in Intensive Care (EPIC) Study. J.A.M.A. 1995; 274: 639-644.

5. Cook D.J., Walter S.D., Cook R.J. et al. Incidence of and risk factors for ventilator-associated pneumonia in critically ill patients. Ann. Intern. Med. 1998; 129: 433-440.

6. Takano Y., Sakamoto O., Suga M. et al. Prognostic factors of nosocomial pneumonia in general wards: a prospective multivariate analysis in Japan. Respir. Med. 2002; 96:18-23.

7. Craven D.E., Steger K.A. Ventilator-associated bacterial pneumonia: challenges in diagnosis, treatment, and prevention. New Horiz. 1998; 6 (2, Suppl.): S30-S45.

8. Craven D.E., Steger K.A., Barber T.W. Preventing nosocomial pneumonia: state of the art and perspectives for the 1990's. Am. J. Med. 1991; 91: 44-53.

9. McEachern R., Campbell G.D. Hospital-acquired pneumonia: epidemiology, etiology and treatment. Infect. Dis. Clin. N. Am. 1998; 12: 761-779.

10. Bonten J.M., Bergmans D.C. Nosocomial pneumonia. In: Mayhall C.G., ed. Hospital epidemiology and infection control. Philadelphia, PA: Williams and Wilkins: 1999. 211-238.

11. Tablan O.C., Anderson L.H., Arden N.H. et al. Guidelines for prevention of nosocomial pneumonia. The Hospital Infection Control Practices Advisory Committee, Centers for Diseases Control and Prevention. Infect. Control. Hosp. Epidemiol. 1994; 15: 587-627.

12. Celis R., Torres A., Gatell J.M. et al. Nosocomial pneumonia: a multivariate analysis of risk and prognosis. Chest 1988; 93: 318-324.

13. Rotstein C., Cummings K.M., Nicolau A.L. et al. Nosocomial infection rates at an oncology center. Infect. Control. 1988; 9: $13-19$.

14. Hanson L.C., Weber D.J., Rutala W.A. et al. Risk factors for nosocomial pneumonia in the elderly. Am. J. Med. 1992; 92: 161-166.

15. Leu H.S., Kaiser D.L., Mori M. et al. Hospital-acquired pneumonia. Attributable mortality and morbidity. Am. J. Epidemiol. 1989; 129: 1258-1267.

16. Bartlett J.G., O'Keele P., Tally F.P. et al. Bacteriology of hospital-acquired pneumonia. Arch. Intern. Med. 1986; 146: 868-871.

17. Louie M., Dyck B., Parker S. et al. Nosocomial pneumonia in a Canadian tertiary care center: a prospective surveillance study. Infect. Control. Hosp. Epidemiol. 1991; 12: 356-363.

18. Gomez J., Esquinas A., Agudo M.D. et al. Retrospective analysis of risk factors and prognosis in non-ventilated patients with nosocomial pneumonia. Eur. J. Clin. Microbiol. Infect. Dis. 1995; 14: 176-181.

19. Hernandez A., Capdevila J.A., Galles C. et al. Factores de riesgo de neumonía nosocomial en pacientes no ventilados. Comunicación al IX Congreso de la SEIMC (n² 257). Enf. Infecc. Microbiol. Clin. 2000; 18 (1, Suppl.): 80.

20. Sopena N., Sabria V. and the Neunos 2000 Study Group. Multicenter Study of Hospital-Acquired Pneumonia in Non-ICU Patients. Chest 2005; 127: 213-219.
21. Herer B., Fuhrman C., Demontrond D. et al. Diagnosis of nosocomial pneumonia in medical ward: repeatability of the protected specimen brush. Eur. Respir. J. 2001; 18: 157-163.

22. Merino-Sanchez M., Alfageme-Michavila I., Lima-Alvarez J. Prognosis in patients with pneumonia and chronic obstructive pulmonary disease. Arch. Bronconeumol. 2005; 41: 607-611.

23. American College of Chest Physicians / Society of Critical Care Medicine Consensus Conference: definitions for sepsis and organ failure and guidelines for the use of innovative therapies in sepsis. Crit. Care Med. 1992; 20: 864-874.

24. Levy M.M., Fink M., Marshall J.C. et al. 2001 SCCM / ESICM / ACCP / ATS / SIS International Sepsis Definitions Conference. Crit. Care Med. 2003; 31: 1250-1256.

25. Rangel-Frausto M.S., Pittet D., Costigan M. et al. The natural history of the systemic inflammatory response syndrome (SIRS): a prospective study. J.A.M.A. 1995; 273: 117-123.

26. Circiumaru B., Baldock G., Cohen J. A prospective study of fever in the intensive care unit. Intensive Care Med. 1999; 25: 668-673.

27. Global Initiative for Chronic Obstructive Lung Disease (GOLD). Global strategy for diagnosis, management, and prevention of chronic obstructive pulmonary disease. NHLBI / WHO workshop report. Last updated 2008. www.goldcopd.org

28. Pugin J., Auckenthaler R., Mili N. et al. Diagnosis of ventilator-associated pneumonia by bacteriologic analysis of bronchoscopic and nonbronchoscopic "blind" bronchoalveolar lavage fluid. Am. Rev. Respir. Dis. 1991; 143: 1121-1129.

29. Luyt C.-E., Chastre J., Fagon J.-Y. Value of the clinical pulmonary infection score for the identification and management of ventilator-associated pneumonia. Intensive Care Med. 2004; 30: 844-852.

30. Knaus W.A., Draper E.A., Wagner D.P., Zimmerman J.E. APACHE II: a severity of disease classification system. Crit. Care Med. 1985; 13: 818-829.

31. Charlson M.E., Pompei P., Ales K.L., MacKenzie C.R. A new method of classifying prognostic comorbidity in longitudinal studies: development and validation. J. Chron. Dis. 1987; 40: 373-383.

32. Dellinger R.P., Levy M.M., Carlet J.M. et al. Surviving Sepsis Campaign: international guidelines for management of severe sepsis and septic shock: 2008. Crit. Care Med. 2008, 36: $296-327$.

33. Авдеев С.Н., Чучалин А.Г. Одышка: механизмы развития, оценка и лечение. Пособие для врачей. М.; 2002. 1-25.

34. Murray P.R., Washington J.A. Microscopic and bacteriologic analysis of expectorated sputum. Mayo Clin. Proc. 1975; 50: $339-344$.

35. National Committee for Clinical Laboratory Standards. Performance standards for antimicrobial susceptibility testing. Philadelphia, PA: NCCLS, 2001; 21 (1).

36. Nseir S., Di Pompeo C., Soubrier S. et al. Impact of ventilator-associated pneumonia on outcome in patients with COPD. Chest 2005; 128: 1650-1656.

37. Torres A., Aznar R., Gatell J.M. et al. Incidence, risk, and prognosis factors of nosocomial pneumonia in mechanically ventilated patients. Am. Rev. Respir. Dis. 1990; 142: 523-528.

38. Rello J., Ausina V., Ricart M. et al. Impact of previous antimicrobial therapy on the etiology and outcome of ventilator-associated pneumonia. Chest 1993; 104: 1230-1235.

39. Taylor G.D., Buchanan-Chell M., Kirkland T. et al. Bacteremic nosocomial pneumonia: a 7-year experience in one institution. Chest 1995; 107: 786-788. 
40. Rello J., Quintana E., Ausina V. et al. Incidence, etiology and outcome of nosocomial pneumonia in mechanically ventilated patients. Chest 1991; 100: 439-444.

41. Johanson W.G., Pierce A.K., Sanford J.P. Changing pharyngeal bacterial flora of hospitalized patients. N. Engl. J. Med. 1969; 281: 1137-1140.

42. Johanson W.G., Pierce A.K., Sanford J.P. et al. Nosocomial respiratory infections with gram-negative bacilli: the significance of colonization of the respiratory tract. Ann. Intern. Med. 1972; 77: 701-706.

43. Carratala J., Gudiol F., Pallares R. et al. Risk factors for nosocomial Legionella pneumophila pneumonia. Am. J. Respir. Crit. Care Med. 1994; 149: 625-629.

44. Castro-Guardiola A., Armengou-Arxe A., Viejo-Rodriguez A. et al. Differential diagnosis between community-acquired pneumonia and non-pneumonia diseases of the chest in the emergency ward. Eur. J. Intern. Med. 2000; 11: 334-339.

45. Almirall J., Bolibar I., Toran P. et al. Contribution of C-reactive protein to the diagnosis and assessment of severity of community-acquired pneumonia. Chest 2004; 125: 1335-1342.

46. Flanders S.A., Stein J., Shochat G. et al. Performance of a bedside C-reactive protein test in the diagnosis of community-acquired pneumonia in adults with acute cough. Am. J. Med. 2004; 116: 529-535.

47. El Solh A., Pineda L., Bouquin P., Mankowski C. Determinants of short and long term functional recovery after hospitalization for community-acquired pneumonia in the elderly: role of inflammatory markers. B.M.C. Geriatr. 2006; 6: 12.

48. Lobo S.M.A., Lobo F.R.M., Bota D.P. et al. C-reactive protein levels correlate with mortality and organ failure in critically Ill patients. Chest 2003; 123: 2043-2049.

49. Coelho L., Povoa P., Almeida E. et al. Usefulness of C-reactive protein in monitoring severe community-acquired pneumonia clinical course. Crit. Care 2007, 11: R92.

50. Hedlund J., Hansson L.O. Procalcitonin and C-reactive protein levels in community-acquired pneumonia: correlation with etiology and prognosis. Infection 2000; 28: 68-73.

51. Matson A., Soni N., Sheldon J. C-reactive protein as a diagnostic test of sepsis in the critically ill. Anaesth. Intensive Care 1991; 19: 182-186.
52. Povoa P., Coelho.L, Almeida E. et al. C-reactive protein as a marker of ventilator-associated pneumonia resolution: a pilot study. Eur. Respir. J. 2005; 25: 804-812.

53. Povoa P., Coelho L., Almeida E. et al. Early identification of intensive care unit-acquired infections with daily monitoring of C-reactive protein: a prospective observational study. Crit. Care 2006; 10: R63.

54. Pinsky M.R., Vincent J.L., Deviere J. et al. Serum cytokine levels in human septic shock: relation to multiplesystem organ failure and mortality. Chest 1993; 103: 565-575.

55. Marty C., Misset B., Tamion F. et al. Circulating interleukin-8 concentrations in patients with multiple organ failure of septic and nonseptic origin. Crit. Care Med. 1994; 22: 673-679.

56. Monton C., Torres A., El-Ebiary M. et al. Cytokine expression in severe pneumonia: a bronchoalveolar lavage study. Crit. Care Med. 1999; 27: 1745-1753.

57. Glynn P., Coakley R., Kilgallen I. et al. Circulating IL-6 and IL-10 in CAP. Thorax 1999; 54: 51-55.

58. Antunes G., Evans S., Lordan J., Frew A. Systemic cytokine levels in community-acquired pneumonia and their association with disease severity. Eur. Respir. J. 2002; 20: 990-995.

59. Igonin A.A., Armstrong V.W., Shipkova M. et al. Circulating cytokines as markers of systemic inflammatory response in severe community-acquired pneumonia. Clin. Biochem. 2004; 37: 204-209.

\section{Информация об авторах}

Авдеев Сергей Николаевич - д. м. н., проф., руководитель клинического отдела ФГУ НИИ пульмонологии ФМБА России; тел: (495) 465-53-64; e-mail: serg_avdeev@list.ru

Баймаканова Гульсара Есенгельдиевна - к. м. н., научный сотрудник ФГУ НИИ пульмонологии ФМБА России; тел: (495) 465-74-15; e-mail: gulsara.bai@mail.ru

Зубаирова Пазилат Алиевна - к. М. Н., научный сотрудник ФГУ "НИИ пульмонологии" ФМБА России; тел: (495) 465-74-15; e-mail: zubairova @mail.ru

Чучалин Александр Григорьевич - д. М. Н., проф., акад. РАМН, директор ФГУ НИИ пульмонологии ФМБА России; тел: (495) 465-52-64

Поступила 42.02.10 (с) Коллектив авторов, 2010 удк 616.24-036.12-06:616.24-002 